\title{
Endothelial Nitric Oxide Synthase (eNOS) Glu298Asp Gene Polymorphism (G894T) as a Risk Factor for Type 2 Diabetes Mellitus in the Tunisian Population
}

\author{
Rihab Sendesni', Nedra Grira1, Oussama Lamine1, Sana Aboulkassem¹, Manel Ayoub1, \\ Nejla Stambouli'1, Ouertani Haroun ${ }^{2}$, Chakib Mazigh ${ }^{1}$, Zied Aouni1 \\ ${ }^{1}$ Biochemistry Department, Research Unit UR12DN02, Military Hospital of Tunis, Tunis, Tunisia \\ ${ }^{2}$ Endocrinology Department, Research Unit UR12DN02, Military Hospital of Tunis, Tunis, Tunisia \\ Email: aouni_zied@yahoo.fr
}

How to cite this paper: Sendesni, R., Grira, N., Lamine, O., Aboulkassem, S., Ayoub, M., Stambouli, N., Haroun, O., Mazigh, C. and Aouni, Z. (2018) Endothelial Nitric Oxide Synthase (eNOS) Glu298Asp Gene Polymorphism (G894T) as a Risk Factor for Type 2 Diabetes Mellitus in the Tunisian Population. Open Access Library Journal, 5: e4171.

https://doi.org/10.4236/oalib.1104171

Received: November 20, 2017

Accepted: January 2, 2018

Published: January 5, 2018

Copyright $\odot 2018$ by authors and Open Access Library Inc.

This work is licensed under the Creative Commons Attribution International License (CC BY 4.0).

http://creativecommons.org/licenses/by/4.0/ (c) () Open Access

\begin{abstract}
Introduction: Diabetes mellitus is a chronic disease whose global expansion gives it the characteristics of a pandemic. Diabetes risk factors are well known. In this work we proposed to study the role of genetic polymorphism of the eNOS G894T gene in the development of diabetes on the one hand and of these degenerative complications other. Methods: We conducted a prospective case-control study in which we included 200 subjects divided into 100 patients with type 2 diabetes and 100 controls in apparent good health. For each patient and control we measured lipid parameters, CRP-us and sought the G894T polymorphism of eNOS gene by PCR-RFLP. Results: The analysis of our results shows a statistically significant elevated TG values $\left(\mathrm{p}<10^{-3}\right)$, Lp (a) $\left(\mathrm{p}<10^{-3}\right)$, and CRP-us $\left(\mathrm{p}<10^{-3}\right)$ in type 2 diabetes compared with controls. The mutated genotypes of GT eNOS gene was significantly more frequent in diabetic patients. In our series, we did not notice any significant difference in genotype or allele frequency between diabetics with and without degenerative complications. Conclusion: The G894T polymorphism of eNOS gene appears to be a risk factor of T2DM. His role in the development of degenerative complications remains proved.
\end{abstract}

\section{Subject Areas \\ Diabetes \& Endocrinology}

Keywords

T2DM, eNOS, The G894T Polymorphism of eNOS Gene 


\section{Introduction}

eNOS is the predominant isoform of NO synthase and responsible for the majority of the nitric oxide production in the vasculature [1]. Nitric oxide (NO) generated by endothelial, is a potent vasodilator and acts as significant key factor in the anti-atherosclerotic properties of the endothelium [2]. It plays an important part in the regulation of blood pressure and regional blood flow, inhibits platelet aggregation and leucocyte adhesion to vascular endothelium, and inhibits vascular smooth-muscle-cell proliferation [3].

Diabetes constitutes one of the major independent cardiovascular risk factors, and patients with this disease suffer from premature cardiovascular morbidity and mortality. Endothelial dysfunction is regarded as an early step in the development of insulin resistance and T2DM as well as important for the atherosclerotic predisposition and cardiovascular complications associated with diabetes [4]. eNOS is presumed to be responsible for most of the endothelial and vascular effects of NO [5]. The eNOS gene has several single nucleotide polymorphisms reported, one of which is G894T. This polymorphism is a transversion $\mathrm{G}$ to $\mathrm{T}$ at nucleotide position 894 in exon 7, resulting in a GAG to GAT substitution in exon 7 with the substitution of glutamine by aspartate (Glu298Asp) [6]. This variant induces a conformational change that is thought to reduce NOS3 activity and has been associated with several effects: increased vasoconstrictive; increased blood pressure response to endurance training; and hypertension, coronary heart disease and myocardial infarction [7] [8]. A reduced bioavailability of NO may result from down-regulated protein expression, depressed activation, or reduced enzymatic function of endothelial nitric oxide synthase (eNOS) or from increased consumption and inactivation of the NO produced [9] [10] [11].

The main objective of the study was to determine the G894T SNP in the eNOS gene such as risk factor for T2DM in Tunisian population.

\section{Materials \& Methods}

\subsection{Study Population}

This case-control study was conducted on 200 subjects divided in two groups, the first group is composed of 100 diabetic patients hospitalized in Endocrinology and Diabetology department of Military Hospital of Tunis in period between February and October 2017. Individuals were diagnosed for T2D according to the criteria given by the American Diabetes Association (ADA) 2011. Hypertensive and dyslipidemic diabetics are included in this study. The second group includes 100 individuals witnessed apparent good health.

For each individual is performed a series of sampling. EDTA tube is used for DNA extraction to determine the SNP of eNOS.

Ethical Consideration Participation was voluntary and verbal consent was acquired from each participant prior to sample collection. Confidentiality of all participants was maintained as no names were requested. The study was approved by the local ethics committee. 


\subsection{DNA Extraction}

The genomic DNA extraction from whole blood was performed by differential precipitation method of proteins by salts "salting out".

The DNA was subsequently lyophilized by then dissolved in 200 to $300 \mu \mathrm{L}$ of $\mathrm{TE}(10 / 1)$ as the size of the medusa then stored at $-20^{\circ} \mathrm{C}$.

The quality of extracted DNA was confirmed by agarose gel $(1.7 \%)$ then revealing by UV.

\subsection{PCR Analysis of G894T SNP (Rs1799983)}

The PCR reaction was performed in a final volume of $50 \mu \mathrm{l}$ containing equal concentration to Forward Primer 5'-AAGGCAGGAGACAGTGGATGGA-3' and reverse primers 5'-CCCAGTCAATCCCTTTGGTGCTCA-3' (10 picomoles), $25 \mathrm{mM}$ desoxynucleotide triphosphate, PCR Buffer, $1.25 \mathrm{U}$ of Taq polymerase (Agilent).

The amplification is carried out after an initial denaturation at $94^{\circ} \mathrm{C}$ for $2 \mathrm{mi}-$ nutes. It takes place in 30 cycles. Each cycle consists of 20 seconds of denaturation, $20 \mathrm{sec}$ hybridization at $55^{\circ} \mathrm{C}$ and 30 seconds extension at $72^{\circ} \mathrm{C}$. A final cycle of $72^{\circ} \mathrm{C}$ for $5 \mathrm{~min}$ fixed the end of the elongation and thus completes the PCR reaction. The hybridization temperature is developed for each pair of primers used for the amplification reaction.

To visualize the PCR products, we made an electrophoresis on agarose gel (1.7\%).

\subsection{Restriction Analysis of G894T SNP}

The digestion was performed in a total volume is $30 \mu \mathrm{l}$ containing $10 \mu \mathrm{l}$ of digested product, $18 \mu \mathrm{l}$ distilled water, $2 \mu \mathrm{l}$ of Buffer Tango buffer, and $1 \mu \mathrm{l}$ Ban II( Eco24I). The mixture was stirred gently with a vortex and then centrifuged for a few seconds and incubated for $16 \mathrm{~h}$ at $37^{\circ} \mathrm{C}$. And the enzyme inactivation takes place at $65^{\circ} \mathrm{C}$ for $20 \mathrm{~min}$. digested PCR products are separated by electrophoresis on agarose gel (1.7\%) (60 min, $120 \mathrm{~V})$.

\subsection{Statistical Analysis}

Statistical analysis of the data collected was analyzed using SPSS Version 19.0 statistics software.

For qualitative variables, we calculated simple frequencies and relative frequencies (percentages). For quantitative variables, we expressed the results are expressed as the arithmetic mean and standard deviation.

The Student $t$ test is used to compare the means of quantitative variables between two groups. The significance of $\mathrm{p}<0.05$ was used.

Odds Ratio was calculated by the crosstabs method.

\section{Results}

In our series, diabetes is significantly more common in men than in women. The 
clinical and demographic characteristics study subjects are shown in Table 1.

Obesity, dyslipidemia, coronary artery disease (CAD) and Hypertension are more common in diabetic patients.

Diabetics have higher concentrations of Lp (a), triglycerides and hsCRP than controls. But we have not noted significant differences in the other parameters (Table 2).

The eNOS G894T gene polymorphism was determined. Analysis chi-square test showed that genotype distribution for the eNOS gene (G894T) in Tunisian population was in accordance with Hardy-Weinberg equilibrium. The genotype frequencies in patients and controls are shown in Table 3.

The frequency of the mutated genotype (GT) is higher in diabetics than in controls with frequencies respectively $54.0 \%$ against $17 \%$.

We have calculated the Odds ratio for the additive and recessive models. Results are presented in Table 4.

Table 1. Clinical and demographic characteristics of study population.

\begin{tabular}{cccc}
\hline Paramètres & $\begin{array}{c}\text { Témoins } \\
(\mathbf{n}=100)\end{array}$ & $\begin{array}{c}\text { Diabétique } \\
(\mathbf{n}=100)\end{array}$ & $\mathbf{P}$ \\
\hline Âge & $39.53 \pm 10.980$ & $56.51 \pm 9.748$ & $<10^{-3}$ \\
Sex Ratio M/W & 2.57 & 1.17 & $<10^{-3}$ \\
BMI & $27.42 \pm 4.096$ & $29.16 \pm 5.39$ & 0.011 \\
waist size & $102.85 \pm 12.75$ & $104.19 \pm 13.68$ & $\mathrm{NS}$ \\
Hypertension & $0 \%$ & $54.4 \%$ & $<10^{-3}$ \\
Dyslipidemia & $0 \%$ & $65.7 \%$ & $<10^{-3}$ \\
SCA & $0 \%$ & $23.2 \%$ & $<10^{-3}$ \\
Family history & & & $<10^{-3}$ \\
$-\quad$ Obesity & $12 \%$ & $29.6 \%$ & $<10^{-3}$ \\
$-\quad$ T2DM & $40 \%$ & $78.6 \%$ & $<10^{-3}$ \\
$-\quad$ HTA & $34 \%$ & $74.5 \%$ & $<10^{-3}$ \\
$-\quad$ Dyslipidemia & $8 \%$ & $27.6 \%$ & $<10^{-3}$ \\
\hline
\end{tabular}

BMI: Body Mass Index; SCA: Acute Coronary Syndrome; T2DM: Type 2 diabetes mellitus; NS: Non-Significant.

Table 2. Comparison of biological parameter between two groups.

\begin{tabular}{cccc}
\hline Parameters & Controls & Diabetic patients & P \\
\hline Cholesterol (mmol/l) & $4.54 \pm 0.97$ & $4.58 \pm 1.26$ & NS \\
HDLc (mmol/l) & $1.05 \pm 0.28$ & $1.03 \pm 0.27$ & NS \\
LDLc (mmol/l) & $2.62 \pm 0.84$ & $2.70 \pm 1.01$ & NS \\
Triglyceride (mmol/l) & $1.39 \pm 0.70$ & $1.89 \pm 1.15$ & $<10^{-3}$ \\
Apo A (g/l) & $1.32 \pm 0.21$ & $1.37 \pm 0.27$ & NS \\
Apo B (g/l) & $0.85 \pm 0.23$ & $0.89 \pm 0.29$ & NS \\
Apo B/Apo A & $0.66 \pm 0.21$ & $0.66 \pm 0.23$ & NS \\
Lp (a) (g/l) & $0.09 \pm 0.09$ & $0.21 \pm 0.37$ & $<10^{-3}$ \\
hsCRP (mg/l) & $1.63 \pm 1.75$ & $2.75 \pm 2.61$ & $<10^{-3}$ \\
\hline
\end{tabular}

HDLc: High-density lipoprotein cholesterol; LDLc: Low-density lipoprotein cholesterol; Apo A: apolipoprotein A; Apo B: apolipoprotein B; Lp (a): lipoprotein (a); hsCRP: high sensitive C-reactive protein; NS: Non-Significant. 
Table 3. Genotypic frequencies in the two groups.

\begin{tabular}{ccc}
\hline Genotypic frequencies & GG & GT + TT \\
\hline Diabetic (T2DM) & $46.0 \%$ & $54.0 \%$ \\
Control & $83 \%$ & $17 \%$ \\
P & $<10^{-3}$ & $<10^{-3}$ \\
\hline
\end{tabular}

Table 4. Odds Ratio for G897T Genotypes model and phenotype.

\begin{tabular}{ccccc}
\hline Genotypes model & T2DM & Controls & OR & P \\
\hline $\begin{array}{c}\text { Dominant model } \\
\text { GT + TT }\end{array}$ & $54 \%$ & $17 \%$ & 5.8 & $10^{-3}$ \\
GG & $46 \%$ & $84 \%$ & & \\
Recessive model & & & & NS \\
GG + GT & $100 \%$ & $100 \%$ & 0.5 & P \\
TT & 0 & $1 \%$ & & \\
\hline Phenotype & T2DM & Controls & OR & \\
\hline Additive model & & & & \\
G & $0.72 \%$ & $0.91 \%$ & 3.97 & \\
T & $0.28 \%$ & $0.09 \%$ & & \\
\hline
\end{tabular}

\section{Discussion}

T2DM is a complex disorder of the endocrine and metabolic system. Several interactions between genetic and environmental factors are proposed to contribute to the pathogenesis of the disease.

The present study showed, such as previous one, that the risk of T2DM increases with age, obesity and lack of physical activity [12]. The analysis of our results shows that BMI was significantly higher in diabetics.

The results of our study shows a statistically significant rise in the hsCRP values in diabetic subjects compared to controls. Elevations in CRP are associated with an increased risk for insulin resistance which contributes to endothelial dysfunction, predisposing the endothelium to a hyper inflammatory and thrombotic condition [13].

Several polymorphisms (SNPs) have been described for the eNOS gene. The G894T polymorphism of the eNOS gene is a nucleotide $\mathrm{G}$ to $\mathrm{T}$ transversion at position 894 [14]. In our series, the G894T polymorphism of eNOS gene was found in $54 \%$ of diabetic patients against $17 \%$ of controls. This difference was statistically significant $\left(\mathrm{p}<10^{-3}\right)$, with an $\mathrm{OR}=5.8$, confidence interval $95 \%=$ 3.017 to 11.14, $\left(\mathrm{p}<10^{-3}\right)$. Our founding is similar to that of Angeline and al. [15]. The authors showed a significant association between G894T eNOS gene polymorphism and type 2 diabetes $(\mathrm{OR}=5.289$, confidence interval $95 \%=2.954$ 9.470). The frequencies of this genotype differ from one population to another. Indeed, Nishevitha and al. [16] reported that this genotype is present in $51.8 \%$ of the Italian population reached T2DM, $8.1 \%$ of the Chinese population, $28.02 \%$ of the Indian population in the north and $25,7 \%$ in the population of southern India. In addition to the difference in ethnicity, and outside environmental factors, other genetic factors may play an important role in the pathogenesis of the 
disease such that the gene-gene interaction which is responsible for the variation between populations and even between people of the same ethnic group [16]. The relationship between the T2DM and polymorphism of eNOS has been shown in other studies, Monti and al., showed that $894 \mathrm{~T}$ allele was more common among Italian patients with type 2 diabetes compared to normal controls [17]. The presence of the variant $894 \mathrm{~T}$ was also associated with hyperglycemia persists among Chinese subjects [18]. Similarly for the population of South Indian the same result was found [19] with a percentage of $75 \%$ of mutated genotype (GT + TT) among type 2 diabetics against $29.37 \%$ in controls [14]. For Korean patients with T2DM, the GT genotype was associated with the progression of diabetic nephropathy [20]. However, they reported that there was no significant difference in the G894T eNOS polymorphism among Mexican-Americans with diabetes and control from Japan, Taiwan, or Finland [18].

Several hypotheses have been advanced to explain the relationship between this polymorphism of the eNOS gene and type 2 diabetes.

NO may play a role in insulin resistance and type 2 diabetes .NO is known to modulate the metabolism of glucose and hepatic and peripheral insulin secretion [13]. Indeed, endothelial dysfunction and decreased production of nitric oxide (NO) by endothelial NO synthase (eNOS) is involved in the pathogenesis of insulin resistance and hypertension [21]. The polymorphic variants of the eNOS gene are associated with high blood pressure and insulin resistance in different populations [22]. Nitric oxide (NO), is an important factor in the regulation of vascular function, is also supposed to have an important role in maintaining glucose homeostasis contributing to the modulation of peripheral sensitivity to the insulin and optionally the secretion of insulin. The vascular action of insulin, consists in increasing the endothelial NO production, this effect is impaired during the IR; it is a cardinal sign in all cases of insulin resistance such as obesity, type 2 diabetes and metabolic syndrome [23]. Endothelial dysfunction is an important clinical feature of diabetes. Signaling pathways responsible for the activation of eNOS are changed in the endothelial cells of patients with diabetes. The decreased eNOS activation by insulin was greatly attenuated in endothelial cells from diabetic patients indicates the presence of the endothelial insulin resistance [24].

Diabetes and insulin resistance are characterized, at least in part by endothelial dysfunction and potentially by altered expression of eNOS and NO production [22].

\section{Conclusion}

This study found a strong independent association between the G894T eNOS gene polymorphism and T2DM.

\section{Acknowledgements}

We thank everyone who we assist in achieving this work either Nursing in Ser- 
vice of Endocrinology and diabetes and technician of biochemistry laboratory in Hospital Principal Military instructions of Tunis that perform bioassays.

\section{Ethical Consideration}

Participation was voluntary and verbal consent was acquired from each participant prior to sample collection. Confidentiality of all participants was maintained as no names were requested.

\section{References}

[1] Moncada, S. and Higgs, E.A. (2006) The Discovery of Nitric Oxide and Its Role in Vascular Biology. British Journal of Pharmacology, 147, 193-201. https://doi.org/10.1038/sj.bjp.0706458

[2] Park, K.W., You, K.H., Oh, S., Chae, I.H., Kim, H.S., Oh, B.H., et al. (2004) Association of Endothelial Constitutive Nitric Oxide Synthase Gene Polymorphism with Acute Coronary Syndrome in Koreans. Heart, 90, 282-285. https://doi.org/10.1136/hrt.2002.003616

[3] Ignarro, L.J., Cirino, G., Casini, A., et al. (1999) Nitric Oxide as a Signaling Molecule in the Vascular System: An Overview. Journal of Cardiovascular Pharmacology, 34, 879-886. https://doi.org/10.1097/00005344-199912000-00016

[4] Creager, M.A., Luscher, T.F., Cosentino, F. and Beckman, J.A. (2003) Diabetes and Vascular Disease: Pathophysiology, Clinical Consequences, and Medical Therapy: Part I. Circulation, 108, 1527-1532. https://doi.org/10.1161/01.CIR.0000091257.27563.32

[5] Markus, H.S., Ruigrok, Y., Ali, N., et al. (1998) Endothelial Nitric Oxide Synthase exon 7 Polymorphism, Ischemic Cerebrovascular Disease, and Carotid Atheroma. Stroke, 29, 1908-1911. https://doi.org/10.1161/01.STR.29.9.1908

[6] Azmy, R., Dawood, A., Kilany, A., El-Ghobashy, Y., Ellakwa, A.F. and El-Daly, M. (2012) Association Analysis of Genetic Variations of eNOS and $\alpha 2 \beta 1$ Integrin Genes with Type 2 Diabetic Retinopathy. The Application of Clinical Genetics, 5 , 55-65.

[7] Lembo, G., De Luca, N., Battagli, C., et al. (2001) A Common Variant of Endothelial Nitric Oxide Synthase (Glu298Asp) Is an Independent Risk Factor for Carotid Atherosclerosis. Stroke, 32, 735-740. https://doi.org/10.1161/01.STR.32.3.735

[8] Karvonen, J., Kauma, H., Kervinen, K., et al. (2002) Endothelial Nitric Oxide Synthase Gene Glu298Asp Polymorphism and Blood Pressure, Left Ventricular Mass and Carotid Artery Atherosclerosis in a Population-Based Cohort. Journal of Internal Medicine, 251, 102-110. https://doi.org/10.1046/j.1365-2796.2002.00933.x

[9] Forstermann, U. (2006) Janus-Faced Role of Endothelial NO Synthase in Vascular Disease: Uncoupling of Oxygen Reduction from NO Synthesis and Its Pharmacological Reversal. Biological Chemistry, 387, 1521-1533.

https://doi.org/10.1515/BC.2006.190

[10] Tai, S.C., Robb, G.B. and Marsden, P.A. (2004) Endothelial Nitric Oxide Synthase: A New Paradigm for Gene Regulation in the Injured Blood Vessel. Arteriosclerosis, Thrombosis, and Vascular Biology, 24, 405-412. https://doi.org/10.1161/01.ATV.0000109171.50229.33

[11] Leighton, F., Miranda-Rottmann, S. and Urquiaga, I. (2006) A Central Role of eNOS in the Protective Effect of Wine Against Metabolic Syndrome. Cell Biochemi- 
stry and Function, 24, 291-298.

[12] Evans, J.L., Goldfine, I.D. and Maddux, B.A. (2002) Oxidative Stress and Stress Activated Signaling Pathways: A Unifying Hypothesis of Type 2 Diabetes. Endocrine Reviews, 23, 599-622. https://doi.org/10.1210/er.2001-0039

[13] Dellamea, S.B., Ferreira Pinto, C.L., Leitão, B.C., Santos, G.K. and Santos Canani, H.L. (2014) Endothelial Nitric Oxide Synthase Gene Polymorphisms and Risk of Diabetic Nephropathy: A Systematic Review and Meta-Analysis. BMC Medical Genetics, 15-19.

[14] Veldman, B.A., Spiering, W., Doevendans, P.A., Vervoort, G., Kroon, A.A., et al. (2002) The Glu298Asp Polymorphism of the NOS 3 Gene as a Determinant of the Baseline Production of Nitric Oxide. Journal of Hypertension, 2023-2027. https://doi.org/10.1097/00004872-200210000-00022

[15] Angeline, T., Krithiga, H.R., Isabel, W., Asirvatham, A.J. and Poornima, A. (2011) Endothelial Nitric Oxide Synthase Gene Polymorphism (G894T) and Diabetes Mellitus (Type II) among South Indians. Oxidative Medicine and Cellular Longevity, 462-467. https://doi.org/10.1155/2011/462607

[16] Nishevitha, N.S., Angeline, T. and Jeyaraj, N. (2009) Endothelial Nitric Oxide Synthase (eNOS) Glu298àAsp Polymorphism (G894T) among South Indians. Indian Journal of Medical Research, 129, 68-71.

[17] Monti, L.D., Barlassina, C., Citterio, L., et al. (2003) Endothelial Nitric Oxide Synthase Polymorphisms Are Associated with Type 2 Diabetes and the Insulin Resistance Syndrome. Diabetes, 2003, 1270-1275. https://doi.org/10.2337/diabetes.52.5.1270

[18] Bressler, J., Pankow, J.S., Coresh, J. and Boerwinkle, E. (2013) Interaction between the NOS3 Gene and Obesity as a Determinant of Risk of Type 2 Diabetes: The Atherosclerosis Risk in Communities Study. PLoS ONE, 8, e79466. https://doi.org/10.1371/journal.pone.0079466

[19] Cheema, B.S., Kohli, H.S., Sharma, R., Bhansali, A. and Khullar, M. (2012) Endothelial Nitric Oxide Synthase Gene Polymorphism and Type 2 Diabetic Retinopathy among Asian Indians. Acta Diabetologica, 49, 481-488. https://doi.org/1007/s00592-012-0437-7

[20] Shin, Y., Baek, S.H., Chang, K.Y., Park, C.W., Yang, C.W., et al. (2004) Relations between eNOS Glu298Asp Polymorphism and Progression of Diabetic Nephropathy. Diabetes Research and Clinical Practice, 65, 257-265. https://doi.org/10.1016/j.diabres.2004.01.010

[21] Zhao, C.X., Xu, X., Cuil, Y., Wang, P., Wei, X., Yang, S., Edin, M.L., Zeldin, D.C. and Wang, D.W. (2008) Increased Endothelial Nitric-Oxide Synthase Expression Reduces Hypertension and Hyperinsulinemia in Fructose-Treated Rats. JPET, 328, 610-620. https://doi.org/10.1124/jpet.108.143396

[22] Vecoli, C., Novelli, M., Pippa, A., Giacopelli, D., Beffy, P., Masiello, P., L’Abbate, A. and Neglia, D. (2014) Partial Deletion of eNOS Gene Causes Hyperinsulinemic State, Unbalance of Cardiac Insulin Signaling Pathways and Coronary Dysfunction Independently of High Fat Diet. PLoS ONE, 8, e104156.

[23] Sally, M., Vijay, S. and McNeill (2009) Insulin Resistance and Endothelial Dysfunction: Are Epoxyeicosatrienoic Acids the Link? Experimental \& Clinical Cardiology, 14, 41-50.

[24] Tabit, C.E., Shenouda, S.M., Holbrook, M., Fetterman, J.L., Kiani, S., Frame, A.A., Kluge, M.A., Held, A., Dohadwala, M., Gokce, N., Farb, M., Rosenzweig, J., Ruder- 
man, N., Vita, J.A. and Hamburg, N.M. (2013) Protein Kinase-C Beta Contributes to Impaired Endothelial Insulin Signaling in Humans with Diabetes Mellitus. Circulation, 127, 86-95. https://doi.org/10.1161/CIRCULATIONAHA.112.127514

\section{Abbreviations}

T2DM: type 2 diabetes mellitus;

IR: insulin resistance;

eNOS: endothelial Nitric Oxide Synthase;

SNP: single Nucleotide polymorphism;

NO: Nitric oxide;

CRPus: $\mathrm{C}$ reactive proteinultra-sensitive;

HTA: high blood pressure;

SCA: acute coronary syndrome;

OR: Odds Ratio;

IC: confiden ceinterval. 